\title{
Study on Environmental Pollution and Control Countermeasures of Agricultural and Rural Areas in Jiangsu Province
}

\author{
Juan Chen a, Guosheng Ma ${ }^{\mathrm{b}, *}$ \\ Suzhou Polytechnic Institute of Agriculture, Suzhou, Jiangsu, 215008 \\ aemail:39340830@qq.com, bemail:goshinema@163.com, *Corresponding author
}

\begin{abstract}
Keywords: Jiangsu Province, agricultural and rural areas, ten years, environmental pollution, control countermeasures.

Abstract. Based on the combination of typical research and literature, this paper analyzes the current situation of agricultural and rural environmental pollution in Jiangsu Province in the past decade and the causes of environmental pollution in agricultural and rural areas of this province. Then it puts forward countermeasures for environmental pollution control. Studies have shown that in the past ten years, the complex causes of environmental pollution in Jiangsu's agricultural and rural areas include the large proportion of nitrogen and phosphorus pollution, the large amount of livestock and poultry manure, the heavily polluted aquaculture and non-point source of planting, the domestic pollution, and lack of laws and regulations, policy input mechanism and effective governance measures. The countermeasures put forward are mainly included in effective development of ecological recycling agriculture, establishment of rural environmental management system, implementation of the policy of ecological direct subsidy and supervision of capital investment.
\end{abstract}

\section{Introduction}

In the past ten years, with the rapid economic and social development of Jiangsu Province, the problem of agricultural and rural environmental pollution has gradually emerged. The cyanobacteria of lakes such as Taihu Lake and Hongze Lake have erupted year after year, and the environmental conditions are not optimistic.

This problem has become a bottleneck restricting water pollution control, rural environmental improvement and sustainable agricultural development, which has constrained the construction of ecological civilization.

\section{Status of environmental pollution in agriculture and rural areas in Jiangsu Province}

\section{Complex environmental pollution sources}

The survey shows that there are mainly seven sources of non-point source pollution in agricultural and rural areas in Jiangsu Province: domestic garbage, domestic sewage, crop straw, livestock and poultry manure and sewage, aquaculture tail water, excessive application of chemical fertilizer, and excessive application of pesticides. Even listed companies occupy farmland for pollutant discharge, resulting in secondary pollution. For example, million tons of steel slag from Shagang Group have been disposed of on the Yangtze River, covering an area of about 135 hectares. Among them, the nature of land use of 10.4 hectares land in Qixin Village, Leyu Town, Zhangjiagang City has been arbitrarily changed ${ }^{[1]}$.

According to the survey results of the agricultural and rural environmental pollution in Suzhou City, from the perspective of source structure, the agricultural and rural environmental pollution here has both non-point source and point source, mainly from planting, livestock and poultry farming, aquaculture, rural life, rural industry, and urban waste transfer, industrial and sewage treatment plant emissions, rural tourism and alien biological invasion ${ }^{[2]}$.

\section{A large proportion of nitrogen and phosphorus pollution}

According to the results of the National Pollution Source Survey, agriculture has become a major source of pollution, and is the main source of chemical oxygen demand, total nitrogen, and total 
phosphorus emissions. Among them, chemical oxygen demand accounts for $43.7 \%$ of total emissions, and the total nitrogen accounts for $57.2 \%$, and the total phosphorus accounts for $67.4 \%$.

The Environmental Quality Bulletin and Annual Report of Jiangsu Province from 2008 to 2017 indicate that the total nitrogen in Taihu Lake was in the V Class or the inferior V Class, and the total phosphorus was in the IV standard. The annual average concentration of total nitrogen was maintained between 1.65 and $2.47 \mathrm{mg} / \mathrm{L}$, the annual average concentration of total phosphorus was maintained between 1.65 and $2.47 \mathrm{mg} / \mathrm{L}$, and the cyanobacterial bloom was maintained between 78 and 113 (Table 1). As of 2017, the overall water quality of Taihu Lake was in Category V, the average concentration of total nitrogen was $1.74 \mathrm{mg} / \mathrm{L}$, the average concentration of total phosphorus was $0.064 \mathrm{mg} / \mathrm{L}$, and the annual cyanobacteria bloom was 113 times. According to the water environment quality of Jiangsu Province in August 2017, the water quality compliance rate of 137 key sections in the Taihu Basin was only $65.7 \%^{[3]}$.

The proportion of agricultural pollution sources in Jiangsu Province is close to the national level, accounting for a large part of total emissions. The contribution of nitrogen and phosphorus in agricultural discharges in the Taihu Lake Basin accounts for more than half ${ }^{[4-6]}$, and the pollution situation is very grim.

Table 1 Changes in nitrogen and phosphorus pollution in Taihu Lake from 2008 to 2017

\begin{tabular}{|c|c|c|c|c|c|}
\hline \multirow[t]{2}{*}{ Year } & \multicolumn{2}{|c|}{$\mathrm{TN}$} & \multicolumn{2}{|l|}{$\mathrm{TP}$} & \multirow{2}{*}{$\begin{array}{c}\text { Cyanobacterial } \\
\text { Bloom (time / } \\
\text { year) }\end{array}$} \\
\hline & $\begin{array}{c}\text { Annual Average } \\
\text { Concentration } \\
(\mathrm{mg} / \mathrm{L})\end{array}$ & $\begin{array}{l}\text { Water Quality } \\
\text { Standard }\end{array}$ & $\begin{array}{c}\text { Annual Average } \\
\text { Concentration } \\
(\mathrm{mg} / \mathrm{L})\end{array}$ & $\begin{array}{c}\text { Water } \\
\text { Quality } \\
\text { Standard }\end{array}$ & \\
\hline 2017 & 1.65 & V Class & 0.081 & IV Class & 113 \\
\hline 2016 & 1.74 & V Class & 0.064 & IV Class & 95 \\
\hline 2015 & 1.81 & V Class & $0.059^{*}$ & IV Class & 91 \\
\hline 2014 & 1.96 & V Class & $0.060 *$ & IV Class & 81 \\
\hline 2013 & $2.13 *$ & Inferior V Class & 0.069 & IV Class & 94 \\
\hline 2012 & $2.16^{*}$ & Inferior V Class & $0.061 *$ & IV Class & 85 \\
\hline 2011 & $2.16^{*}$ & Inferior V Class & $0.068 *$ & IV Class & 82 \\
\hline 2010 & $2.41 *$ & Inferior V Class & $0.062 *$ & IV Class & 78 \\
\hline 2009 & $2.47 *$ & Inferior V Class & $0.069 *$ & IV Class & / \\
\hline 2008 & 2.40 & Inferior V Class & $0.069 *$ & IV Class & 104 \\
\hline
\end{tabular}

Note: 1. The data is derived from the Jiangsu Provincial Environmental Quality Bulletin and the Annual Report; 2.* is based on the annual total concentration decrease or increase percentage Jiangsu Environmental Quality Bulletin or the Annual Report of 2009-2016; 3./ indicates there is no data.

\section{Large amount of livestock and poultry manure pollution}

In the six years from 2010 to 2016, the structure of livestock and poultry farming in Jiangsu Province was adjusted, but the scale of aquaculture remained unchanged. The total amount of pig breeding increased steadily, that of sheep farming increased by $9.02 \%$, and poultry farming decreased by $12.45 \%$ (Table 2).

The scale aquaculture in Jiangsu has developed rapidly, with 130,000 large-scale farms, including 10,500 in the Taihu Basin and 2,200 large and medium-sized livestock and poultry farms. With the development of agricultural scale cultivation and livestock-scale aquaculture, the divorce between agricultural and animal husbandry has become increasingly serious. On the one hand, a large number of crops require chemical fertilizers; on the other hand, a large number of livestock and poultry manures have not been removed, and they are not treated in a timely and effective manner, only treated in the rainy season. 
According to statistics, the annual production of livestock and poultry manure pollutants in Jiangsu is about 48 million tons, while the comprehensive treatment utilization rate is only about $65 \%$. The untreated livestock wastes enter the water body in large quantities, resulting in a series of serious environmental problems which have become an important source of pollution for eutrophication of water bodies.

In terms of regions, the livestock and poultry farms in the southern part of Jiangsu has been effectively treated, while that in the northern part failed to be treated. The number of scattered aquaculture in southern Jiangsu is small, while in the central and northern Jiangsu regions, more than $65 \%$ of the households have livestock and poultry farming, and livestock manure pile up in the open air. Taking Suzhou as an example, the total nitrogen and total phosphorus emissions of livestock and poultry farming reached $1132.73 \mathrm{t} / \mathrm{a}$ and $4221.31 \mathrm{t} / \mathrm{a}$, respectively ${ }^{[2]}$.

Table 2 Changes in the scale of livestock and poultry breeding in Jiangsu Province from 2010 to 2016

\begin{tabular}{ccccc}
\hline $\begin{array}{c}\text { Yearly } \\
\text { Variation }\end{array}$ & $\begin{array}{c}\text { Pig Slaughter } \\
(10,000 \text { heads })\end{array}$ & $\begin{array}{c}\text { Cow on hand } \\
(10 \text { thousand })\end{array}$ & $\begin{array}{c}\text { Sheep Slaughter } \\
(10 \text { thousand })\end{array}$ & $\begin{array}{c}\text { Livestock slaughter } \\
(100 \text { million })\end{array}$ \\
\hline 2016 & 2847.3 & $/$ & 739.27 & 7.15 \\
2010 & 2847.0 & 35.7 & 672.50 & 8.04 \\
Variation & $+0.01 \%$ & $/$ & $+9.02 \%$ & $-12.45 \%$ \\
\hline
\end{tabular}

Note: 1. The data comes from the Jiangsu Rural Statistical Yearbook; 2./ means no data.

\section{Heavily Polluted Aquaculture}

In recent years, although the Taihu purse seine culture is gradually being demolished, there are still a large number of purse seine cultures in other lakes such as Yangcheng Lake, Huaihe River Basin and Hongze Lake in the Taihu Lake Basin. There are a large number of ponds in the waters near the major lakes including Taihu Lake.

Aquaculture water contains a large amount of nitrogen, phosphorus, antibiotics, etc., and the direct discharge of tail water causes serious pollution to the environment. Taking Suzhou as an example, the total nitrogen and total phosphorus emissions from pond aquaculture reach1025.67 t/a and 78.69 t/a, respectively ${ }^{[2]}$.

\section{Serious non-point source pollution in the planting industry}

According to statistics, the average fertilizer use in Jiangsu Province is $750-900 \mathrm{~kg} / \mathrm{ha}$, while the national level is $390 \mathrm{~kg} / \mathrm{ha}$ in the same period; the average pesticide use in the whole province is $22.5-30.0 \mathrm{~kg} / \mathrm{ha}$, while the national level is $12.0 \mathrm{~kg} / \mathrm{ha}$ in the same period. The application level of farmland organic fertilizer in the whole province is mostly less than $6000 \mathrm{~kg} / \mathrm{ha}$, and the application level is low; the annual production of crop straw is more than 40 million tons, and the comprehensive utilization rate is less than $60 \%{ }^{[5]}$.

Taking Suzhou as an example, the total nitrogen and total phosphorus emissions of agricultural crops alone reach 3,297.54 t/a and $608.06 \mathrm{t} / \mathrm{a}$, respectively ${ }^{[2]}$.

\section{Intensified rural life pollution}

According to statistics, in addition to Chengguan Town and the towns that are included in the scope of urban planning and construction, Jiangsu has 1002 townships, 15,109 administrative villages, more than 130,000 natural villages, and a rural population of more than 36.6 million. It is estimated that the annual rural domestic garbage in the province produces more than 10 million tons, and domestic sewage is about 1 billion tons. Due to the scattered rural living, the influence of farmers' living habits on the environment is increasingly serious. The production and domestic sewage are discharged at will, the domestic garbage is piled up anywhere, the manure is not treated, or the septic tank is directly discharged into the river, lacking effective management. 


\section{Analysis of the causes of environmental pollution in agricultural and rural areas in Jiangsu Province}

\section{Lack of governance regulations}

The agricultural production methods and the peasant lifestyle are unreasonable, and the rural areas themselves also produce a large amount of waste. At the same time, as a supporter of rapid urban development, agriculture and rural areas must provide basic agricultural products and leisure tourism functions, as well as more and more urban pollutants. There are no corresponding local regulations for how to effectively manage these rural environmental problems.

\section{Lack of policy input mechanism}

The long-term urban-rural dual structure has resulted in different treatments for urban and rural residents. The agricultural and rural environmental protection facilities are seriously lagging behind. The environmental protection policies, funds and technologies are tilted towards the city. The existing facilities lack effective management and maintenance, and there is almost no governance investment. The sewage treatment facilities in most villages in southern Jiangsu have a low operating rate and lack of long-term mechanism. The central and northern areas of Jiangsu Province are mainly three-formatted septic tanks with poor treatment effects. The treated sewage still contains a large number of organic contaminants.

\section{Lack of effective governance measures}

There is a lack of rural environmental management institutions, and the rural environmental management system lags behind the rural development process. The division of responsibility for environmental protection does not match the nature of rural pollution, and there is no rural environmental supervision system. Without attaching great importance to the transfer of pollution and the pollution it produces, local governments are not in a position to regulate rural environment.

\section{Agricultural and rural environmental pollution control countermeasures in Jiangsu Province}

\section{Effective development of ecological recycling agriculture}

The construction of ecological recycling agriculture should be effectively promoted and the recycling crop straw, livestock manure, waste tail water from farming, fertilizer and tail water lost from farmland should be regarded as the recycling resources to control agricultural and rural non-point source pollution from the source. Implement ecological recycling agricultural projects within $1 \mathrm{~km}^{2}$ of the water body to realize zero discharge of agricultural pollutants, control eutrophication of water bodies from the source, build an ecological breeding chain industrial chain, carry out regional nutrient balance management, and prevent agricultural nitrogen and phosphorus from entering water bodies.

\section{Establishment of a rural environmental management system}

The existing technology promotion service system in the agricultural sector will be used to establish a rural environmental management system, namely, set up an environmental management integrated service station in the rural areas to promote advanced practical technologies that are conducive to environmental protection, farmers' income, and agricultural development. At the same time, the agricultural and rural ecological environmental protection technology will be promoted and trained as an important part of farmers' science and technology training, rural labor transfer training and farmers' quality education project, transforming the unreasonable production and life style, and constructing an effective rural environmental management system.

\section{Implementation of the agricultural ecological direct subsidy policy}

The agricultural ecological direct subsidy policy directly could subsidize farmers who implement ecological environmental management policies and environmentally friendly technologies and guide them to adopt environmentally friendly production and lifestyle. Establish ecological compensation special funds and financial interest subsidies for the recycling of agricultural wastes, and focus on the 
use of livestock and poultry manure resources, comprehensive utilization of straw, agricultural wetland systems, and reduction of fertilizers and pesticides.

\section{Increase the supervision of capital investment}

The government's special funds for environmental protection should be tilted to the countryside, and the rural environmental governance and the operation and maintenance fees for existing projects should be included in the public budget.Standardize and guide all kinds of social capital investment in rural environmental governance, and gradually form a diversified investment and multi-channel investment mechanism. Increase funding supervision to ensure that limited funds play an effective role. Strengthen the authenticity assessment of rural environmental governance performance assessment, timely eliminate unrealistic environmental protection projects, and ensure that environmental protection projects that have been built to meet actual needs can operate long-term.

\section{Acknowledgements}

This research was financially supported by the "Qinglan Project" of Universities in Jiangsu province (Grant NO. 2016-15), Jiangsu province "333 High-level Personnel Training Project" (Grant NO. BRA2016489), and Jiangsu province "Six Talent Peaks Project" (Grant NO. 2016-NY-093).

\section{References}

[1] Min. of Eco. and Env.: Shagang Group's million tons of steel slag dumped the river to threaten the ecological environment of Yangtze River water, on http://www.mep.gov.cn/gkml/sthjbgw/qt/201806/t20180628_445704.htm (2018)

[2] G.S. Ma, L. Li, W.Z. Sheng: Study on the New Normal of Agricultural and Rural Environmental Protection in Suzhou and the Countermeasures, in: International Conference on Applied Mathematics and Mechanics (2016), p. 423-430

[3] Jiangsu Env. Pro. Depart.: The quality of water environment in Jiangsu province in August 2017, on http://hbt.jiangsu.gov.cn/jshbw/hbzl/szyb/201708/t20170822_407797.html(2017)

[4] G.S. Ma, W.Z. Sheng: Construction of demonstration zone for livestock and poultry farming and agricultural nitrogen and phosphorus pollution control in Taihu basin of Jiangsu, Environmental Science and Management, Vol. 41(2016), p. 144-148

[5] G.S. Ma, W.Z. Sheng: Innovation and Countermeasures of industrialization governance of agricultural planting waste in Taihu River Basin, in: Proceedings of the Chinese Academy of Environmental Sciences Annual Conference on Science and Technology(2017), p. 1597-1602

[6] D. Zhang, Y. Zhang and X.H. Song: Investigation and Control Countermeasures of agricultural non-point source pollution in Taihu, Suzhou, Agricultural environment and development, Vol. 6(2009), p. 71-75

[7] SH.Y. Feng, F.T. Qu and SH.D. Zhou, in: Research on environmental management in rural development, Science Press, Peking (2014) 